\title{
Effects of Propylene Glycol on the Physical Properties of Poly(vinyl alcohol) Solutions and Films
}

\author{
Yong Han Cho and Byoung Chul Kim* \\ Division of Applied Chemical and Bio Engineering, Hanyang University, Seoul 133-791, Korea
}

Kyung Sik Dan

Advanced Technology R\&D Center, SKC Co., Ltd., Suwon, Gyeonggi, Korea

Received September 26, 2008; Revised March 10, 2009; Accepted March 11, 2009

\begin{abstract}
To trace the plasticizing effects of propylene glycol (PG) on poly(vinyl alcohol) (PVA), the rheological properties of PVA solutions in dimethyl sulfoxide (DMSO) and the physical properties of PVA films were discussed in terms of PG content. Both properties were closely related to the hydrogen bond breaking effects of PG. The 6 and $12 \mathrm{wt} \%$ PVA solutions containing PG exhibited Bingham behavior, which was more noticeable at lower plasticizer content and higher polymer concentration. The $6 \mathrm{wt} \%$ PVA solutions containing more than $30 \mathrm{wt} \% \mathrm{PG}$ showed a sudden decrease of viscosity over the frequency range of 0.08 and $0.2 \mathrm{rad} / \mathrm{s}$. However, the $12 \mathrm{wt} \%$ PVA solutions showed no viscosity reduction even at a PG content up to $40 \mathrm{wt} \%$. The glass transition temperature of the PVA/PG films was almost linearly decreased with increasing PG content but an abrupt reduction was observed at a plasticizer content $30 \mathrm{wt} \%$, suggesting that the hydrogen bond breaking effects of PG on PVA became dominant between 20 and $30 \mathrm{wt} \%$. This effect was further supported by the similar tendency of the tensile properties.
\end{abstract}

Keywords: poly(vinyl alcohol) solution, poly(vinyl alcohol) film, propylene glycol, rheological properties, hydrogen bond.

\section{Introduction}

Poly(vinyl alcohol) (PVA) is one of the first synthetic polymers produced on a large commercial scale but is still finding various industrial applications such as packaging, textiles, membranes, films, and biomedical materials. ${ }^{1-6}$ PVA is a semicrystalline polymer which has inter- and intramolecular hydrogen bonds, whose degree is greatly dependent on the tacticity of the polymer. ${ }^{7-9}$ PVA has a high glass transition temperature because of high packing density and effective hydrogen bonding resulting from planar zig-zag chain conformation. ${ }^{10}$

As packaging materials the PVA film is too brittle because of high crystallinity. To improve toughness various methods have been devised mostly by regulating crystallinity. In addition, the high degree of hydrogen bonding frequently causes troubles during fabrication because of high and time-dependent viscosity of PVA solutions in organic solvents as reported by Kim et al.. ${ }^{11-13}$ These drawbacks can be overcome by plasticization, which improves impact strength, elongation at break and ductility of PVA films as well. It has long been recognized that introducing glycols to PVA is of help to

*Corresponding Author. E-mail: bckim@hanyang.ac.kr improve toughness of films and to reduce viscosity ${ }^{14}$ Early studies showed that plasticizers reduce thermal properties such as $T_{g}$ and melting temperature. ${ }^{15-17}$ However, little systematic and theoretical study on the rheological and physical properties of PVA containing propylene glycol (PG) has been published, which is valuable for PVA processors.

In this study, the effects of introducing propylene glycol (PG), which plays the role of hydrogen bond breaker in the polymer systems, on the rheological properties of PVA solutions in dimethyl sulfoxide (DMSO) and the thermal and mechanical properties of solution-cast PVA/PG films were investigated in relation with PG content.

\section{Experimental}

Materials. The degree of hydrolysis and molecular weight of PVA were $99 \%$ and $89,000-98,000$, respectively. The resins were vacuum dried at $80{ }^{\circ} \mathrm{C}$ for $24 \mathrm{~h}$ before use. PVA and PG were purchased from Aldrich Co. and a commercial-grade DMSO was used as a solvent without further purification. Since the dissolution conditions may have a profound effect on the rheological and physical properties of the solutions of polar polymers in polar solvents, the dissolution procedure was strictly controlled : The mixture of 
PVA and PG was dissolved in DMSO at $90{ }^{\circ} \mathrm{C}$ for $3 \mathrm{~h}$. The concentrations (X) of PVA in DMSO were 6 and $12 \mathrm{wt} \%$. PG content (Y) was 10, 20, 30 and $40 \mathrm{wt} \%$ to the PVA resin. The samples were coded as PVA-X-Y. The PVA/PG films were prepared as follows : Mixtures of PVA and PG were first dissolved in distilled water, which were solution-cast to PVA/PG films. The films were stabilized for $12 \mathrm{~h}$, then placed in a vacuum oven at $115{ }^{\circ} \mathrm{C}$ for $24 \mathrm{~h}$ to remove the residual solvent.

Measurement of Rheological Properties. An advanced rheometric expansion system (Rheometric Scientific, Inc.) was used to measure the rheological properties of the PVA/ PG/DMSO solution systems. Parallel-plate geometry, with a diameter of $50 \mathrm{~mm}$, was used. For a good reproducibility the effective strain level was determined by tracing the variation of storage modulus $\left(G^{\prime}\right)$ with strain level. The linear viscoelastic regime extended up to the strain level $15 \%$. So the strain level was determined to be $10 \%$. The plate gap was $1 \mathrm{~mm}$. The specimen was stabilized on the plate for 5 min at $90{ }^{\circ} \mathrm{C}$ to fully relax the residual stresses. Frequency-sweep measurement was conducted over the angular frequency range of $0.05-500 \mathrm{rad} / \mathrm{s}$ at $90{ }^{\circ} \mathrm{C}$. In addition, time-sweep measurement was conducted at $0.1 \mathrm{~s}^{-1}$ and at the strain level $5 \%$ at $90{ }^{\circ} \mathrm{C}$.

Measurement of Thermal Properties. The thermal properties of PVA/PG films were measured by differential scanning calorimetry (DSC, TA Instruments, DSC2010) in nitrogen atmosphere. In DSC measurement, the scan rate was $10{ }^{\circ} \mathrm{C} / \mathrm{min}$. The melting temperature $\left(T_{m}\right)$ and enthalpy of fusion $\left(\Delta H_{f}\right)$ of each sample were determined from the maximum and area of the melting peak, respectively.

Measurement of Dynamic Mechanical Properties. The glass transition temperature $\left(T_{g}\right)$ of PVA/PG films was measured by dynamic mechanical thermal analysis (DMTA, TA Instruments, DMA2980). The dynamic mechanical behaviors of samples were measured with forced vibration at frequency $3 \mathrm{~Hz}$ over the temperature range of $-70 \sim 130{ }^{\circ} \mathrm{C}$. The heating rate was $2{ }^{\circ} \mathrm{C} / \mathrm{min}$.

Measurement of Tensile Properties. The mechanical properties of the PVA-cast film were measured at room temperature using an Instron 4465 testing machine, according to the procedures in the ASTM D 638 standard. The gauge length and the crosshead speed were set to $20 \mathrm{~mm}$ and $10 \mathrm{~mm} / \mathrm{min}$, respectively.

\section{Results and Discussion}

Rheological Properties of PVA/PG Solutions in DMSO. Figures 1(a) and 1(b) show variation of dynamic viscosity $\left(\eta^{\prime}\right)$ of 6 and $12 \mathrm{wt} \%$ PVA solutions in DMSO at $90{ }^{\circ} \mathrm{C}$ with PG content, respectively. All PVA solutions exhibit Bingham flow behavior. It is recognized that the solutions of highly polar polymers in highly polar solvents produces pseudostructure, a 3-dimensional physical structure, which
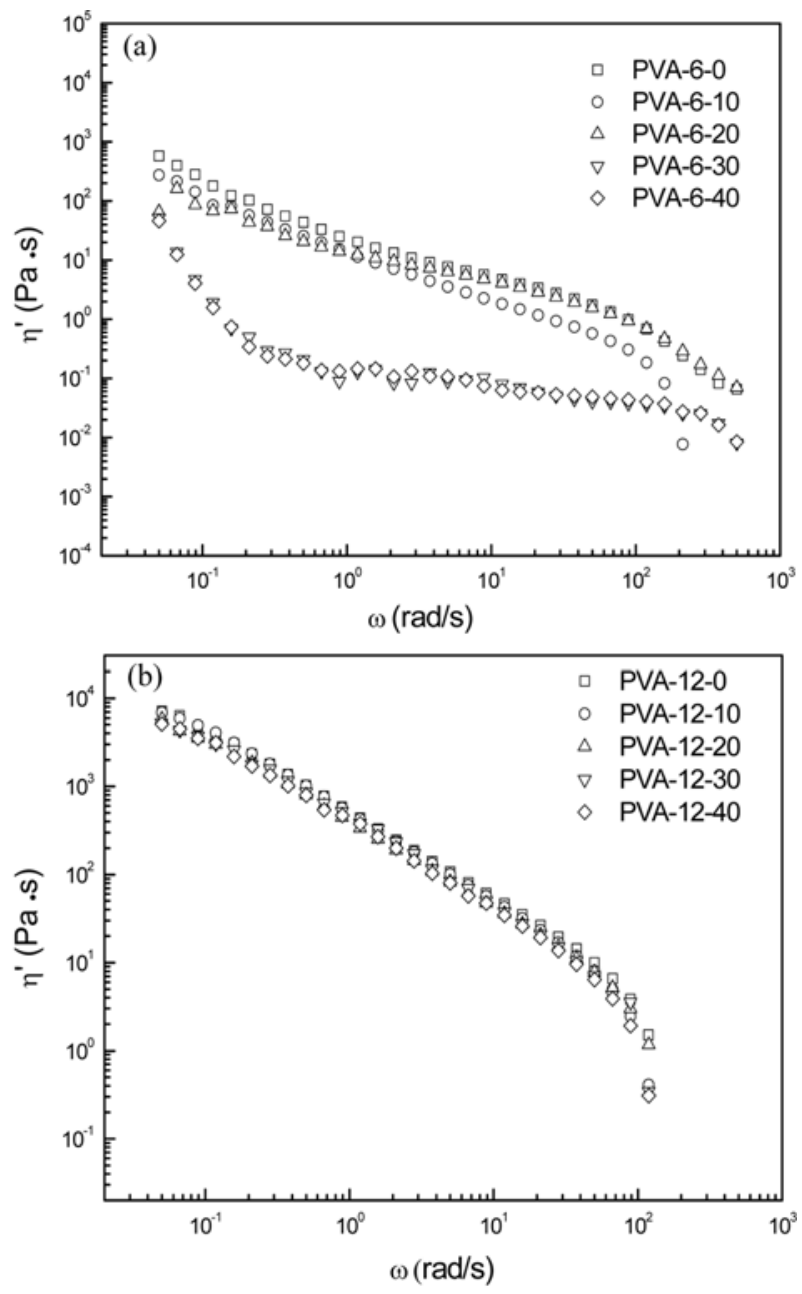

Figure 1. Dynamic viscosity ( $\eta^{\prime}$ ) curve of (a) PVA-6-PG and (b) PVA-12-PG solutions in DMSO at $90{ }^{\circ} \mathrm{C}$.

results in Bingham flow behavior. ${ }^{7,8,10}$ At $12 \mathrm{wt} \%$, the $\eta^{\prime}$ is linearly decreased with increasing frequency and gives almost a straight line over a wide range of frequencies as shown in Figure 1(b). All the solutions give little changes of $\eta^{\prime}$ with PG content, suggesting that the pseudostructure formed by hydrogen bonding is retained over the PG content range observed in the case of $12 \mathrm{wt} \%$ solutions.

On the other hand, $6 \mathrm{wt} \%$ solutions exhibit complicated viscosity curves with PG content. When PG content exceeded $30 \mathrm{wt} \%$, an abrupt drop of $\eta^{\prime}$ is observed in the vicinity of $0.2 \mathrm{rad} / \mathrm{s}$, followed by a plateau region. The difference in viscosity behaviors of 6 and $12 \mathrm{wt} \%$ solutions seems to come from the effectiveness of intermolecular interactions by hydrogen bonding. The physical structure in $6 \mathrm{wt} \%$ solutions is not so strong as that in $12 \mathrm{wt} \%$ solutions. Hence, introducing plasticizer notably weakens the pseudostructure. In consequence, the pseudostructure in $6 \mathrm{wt} \%$ solutions would be broken-down above a critical shear rate, resulting in a sudden drop of viscosity and Newtonian flow 
Effects of Propylene Glycol on the Physical Properties of Poly(vinyl alcohol) Solutions and Films
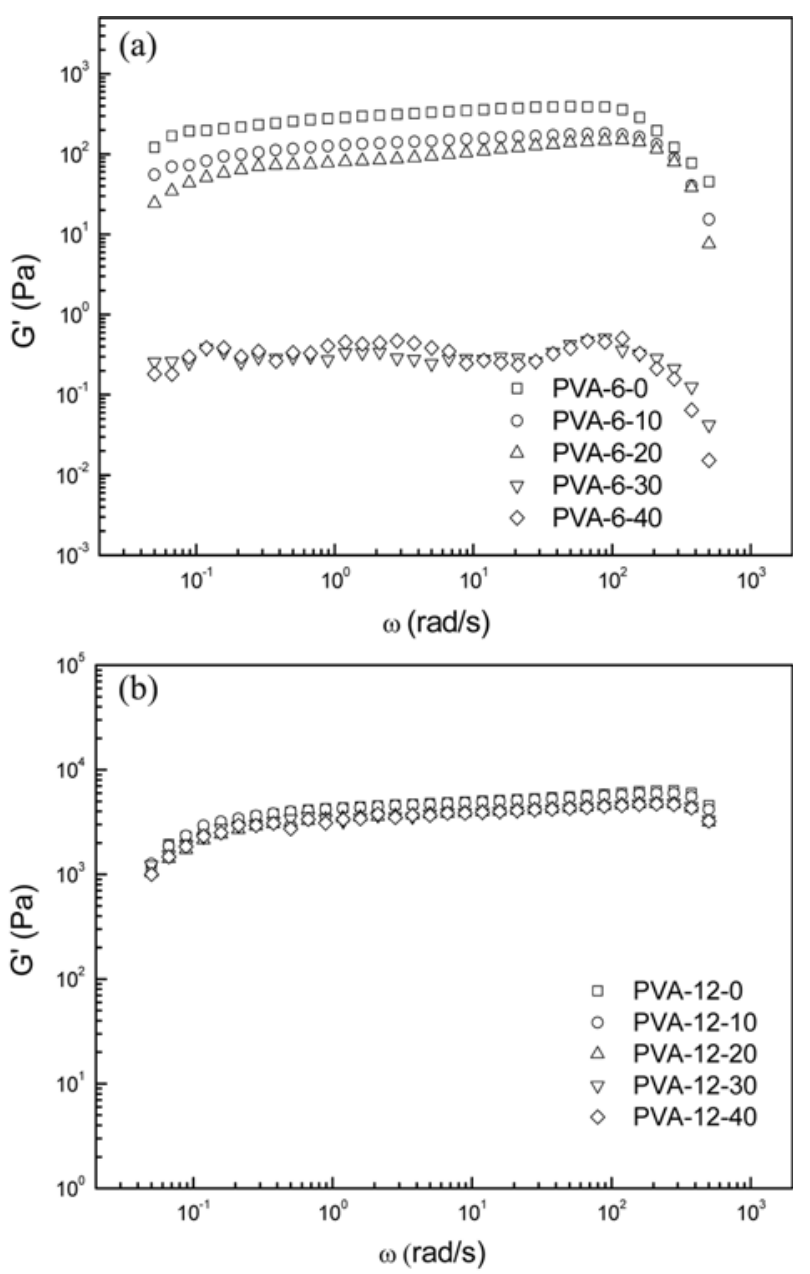

Figure 2. Storage modulus ( $\left.G^{\prime}\right)$ vs. frequency $(\omega)$ for (a) PVA-6PG and (b) PVA-12-PG solutions in DMSO at $90{ }^{\circ} \mathrm{C}$.

behavior followed as shown in Figure 1(a). A closer observation of the curves reveals that partial breakdown of physical structure takes place up to PG content $20 \%$ but whole scale breakdown of the structure occurs above PG content $30 \mathrm{wt} \%$. The storage modulus $\left(G^{\prime}\right)$ curves of the solutions in Figure 2 further ascertain this.

As recognized Bingham body gives a positive value of yield stress which is threshold shear stress to breakdown the 3-dimensional physical structure. ${ }^{18}$ This is originally defined for steady-shear measurement. On the similar concept, the yield value of heterogeneous systems in dynamic shear measurement may be also calculated by modified Casson plot, a plot of square root of loss modulus $\left(G^{\prime \prime}\right)$ versus square root of frequency $(\omega) .^{19}$

$$
G^{\prime \prime 1 / 2}=G_{0}{ }^{\prime 1 / 2}+K^{\prime} \omega^{1 / 2}
$$

In which, $\omega$ is angular frequency, $G_{0}^{\prime \prime}$ is yield stress, and $K^{\prime}$ is constant. The determined values of yield stress of the solutions are given in Table I. As a rule, the yield stress was increased with increasing PVA content and with decreasing
Table I. Yield Stress of PVA/PG Solutions Obtained by Modified Casson Method

\begin{tabular}{cccccc}
\hline $\mathrm{PVA} / \mathrm{PG}$ & $G_{0}^{\prime \prime 1 / 2}(\mathrm{~Pa})$ & $k$ & $\mathrm{PVA} / \mathrm{PG}$ & $G_{0}^{\prime \prime 1 / 2}(\mathrm{~Pa})$ & $k$ \\
\hline $6 / 0$ & 3.43 & 3.87 & $12 / 0$ & 16.24 & 17.58 \\
$6 / 10$ & 2.85 & 2.21 & $12 / 10$ & 15.01 & 15.26 \\
$6 / 20$ & 2.55 & 1.49 & $12 / 20$ & 13.33 & 15.17 \\
$6 / 30$ & 0.27 & 0.27 & $12 / 30$ & 11.45 & 25.96 \\
$6 / 40$ & 0.23 & 0.38 & $12 / 40$ & 9.26 & 30.34 \\
\hline
\end{tabular}
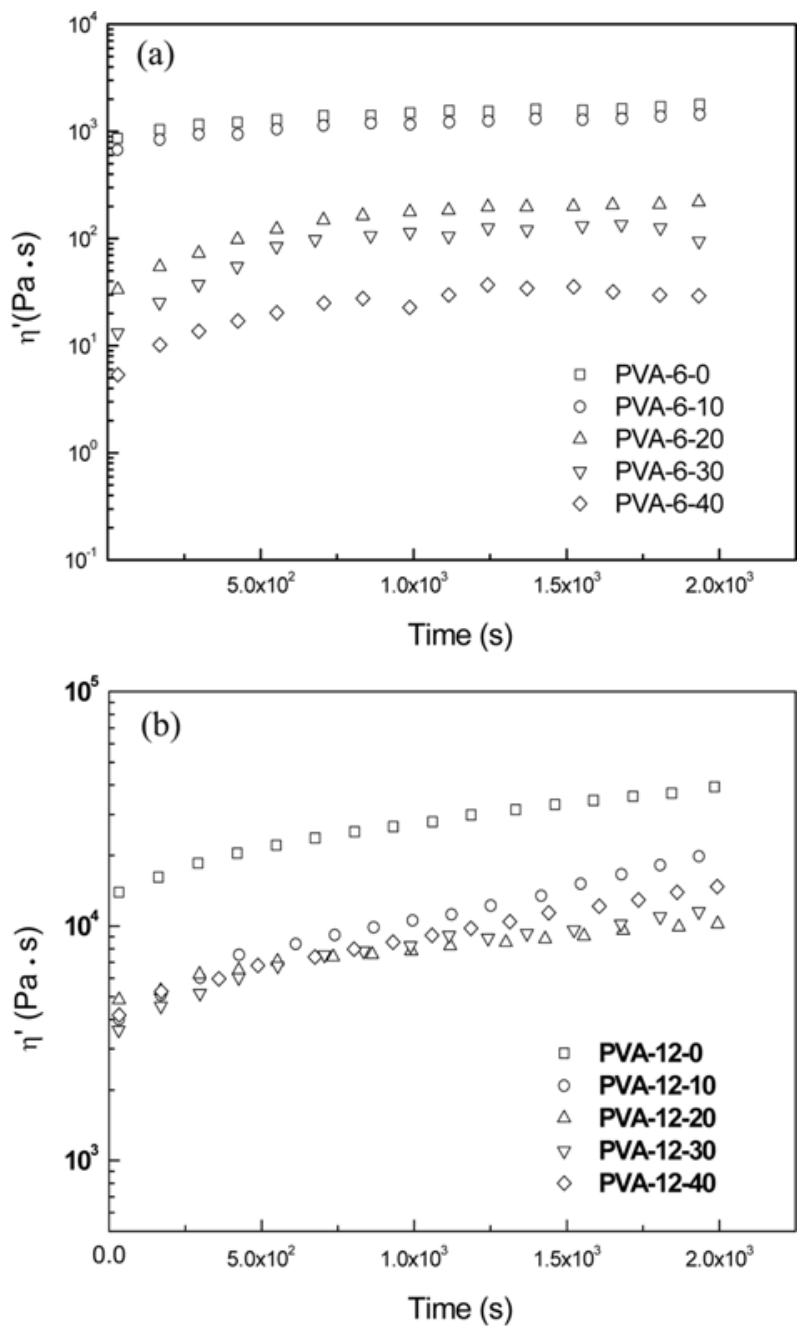

Figure 3. Time dependence of dynamic viscosity $\left(\eta^{\prime}\right)$ versus time of (a) PVA-6-PG and (b) PVA-12-PG solutions in DMSO at $90{ }^{\circ} \mathrm{C}$ at $0.1 \mathrm{~s}^{-1}$.

PG content because of formation of stronger physical structure. This is further ascertained by time-sweep experiment shown in Figure 3. All solutions exhibit a continuous increase of viscosity at constant shear rate over the observed time period, which results from the shear-induced orientation or crystallization.

The loss tangent $(\tan \delta)$ is a quantitative measure of solidlike elastic or liquid-like character of a system. In principle, 

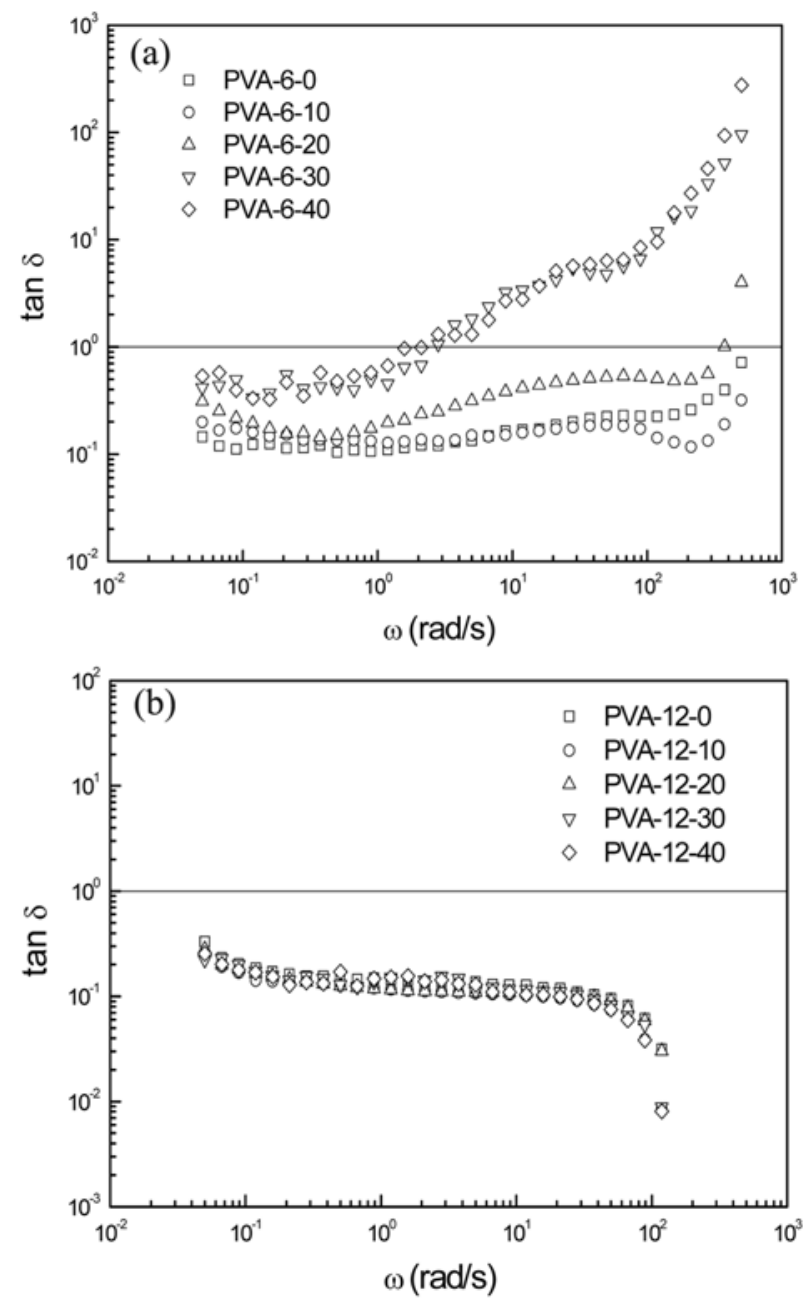

Figure 4. Loss tangent $(\tan \delta$ ) curve for (a) PVA-6-PG and (b) PVA-12-PG solutions in DMSO at $90{ }^{\circ} \mathrm{C}$.

fluid character gets dominant when the $\tan \delta$ value is greater and vice versa. The value of $\tan \delta$ of $\mathrm{PVA} / \mathrm{PG}$ in DMSO at $90{ }^{\circ} \mathrm{C}$ is plotted versus shear rate in Figure 4. The $\tan \delta$ of PVA-12-PG in Figure 4(b) is always less than 1 over the entire frequency range examined irrespective of $\mathrm{PG}$ content. This suggests that the solution systems possess strong physical aggregates of polymer molecules, which act like a local micro gel. On the other hand, PVA-6-PG solutions exhibit higher fluidity particularly at higher PG content as shown in Figure 4(a). At high frequency region, $6 \mathrm{wt} \%$ PVA solutions containing PG more than $30 \mathrm{wt} \%$ show some transition of phase with increasing frequency except the solutions of low PG content.

As well recognized a polymer material has a unique relaxation time $(\lambda)$ on the condition that the polymer material has consistency in structure. In these polar PVA systems, however, the relaxation time would vary because the physical state of the solution is continuously changing according to temperature, shear rate and period of shearing time. ${ }^{11,12}$ In
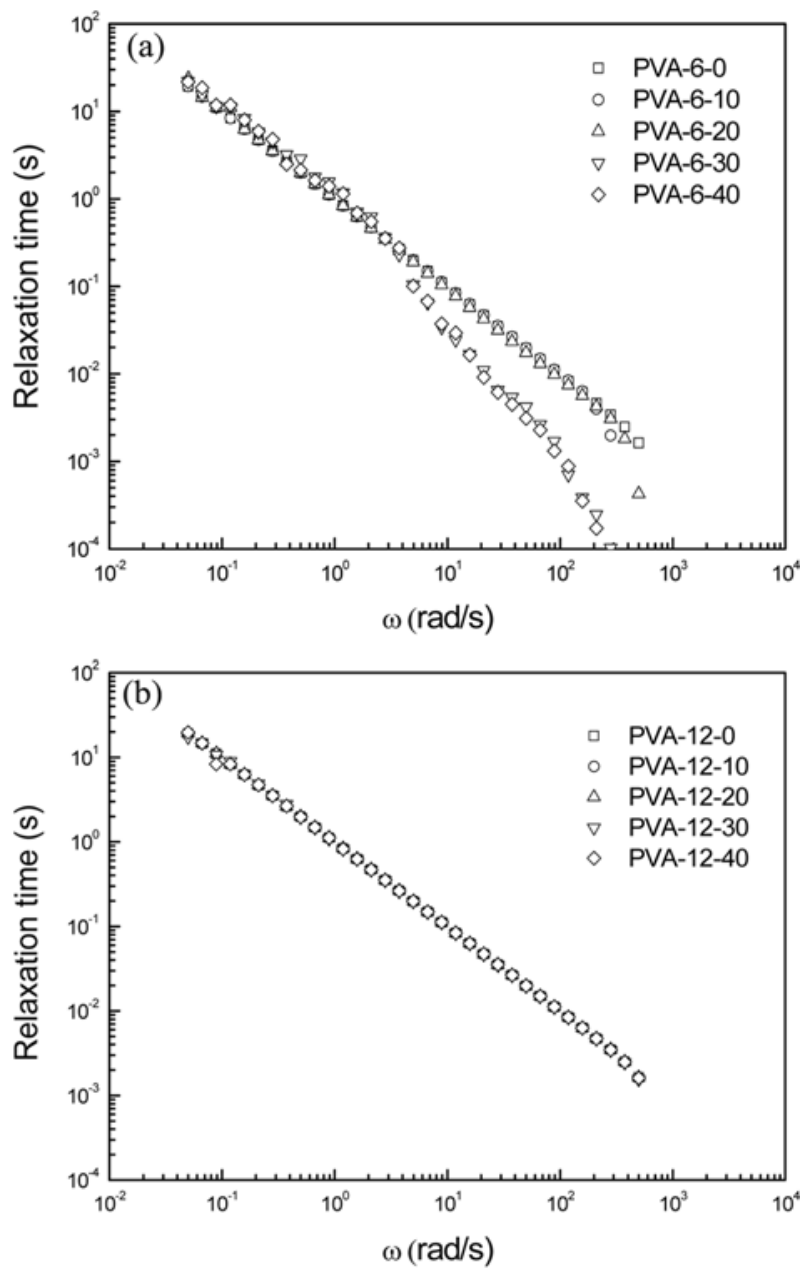

Figure 5. Relaxation time $(\lambda)$ curve for (a) PVA-6-PG and (b) PVA-12-PG solutions in DMSO at $90{ }^{\circ} \mathrm{C}$.

this case, $\lambda$ under dynamic shear can be calculated by eq. (2). ${ }^{20}$

$$
J^{\prime}=G^{\prime} /\left(\left|\eta^{*}\right| \omega\right)^{2}=\lambda /\left|\eta^{*}\right|
$$

In which, $J^{\prime}$ and $\eta^{*}$ are compliance and complex viscosity, respectively. In consequence, the elastic gel character can also be judged by relaxation behavior as shown in Figure 5. If there are some molecular orders or physical structures, much longer $\lambda$ expected because they retard the relaxation of the polymer segments and chains. In the case of $12 \mathrm{wt} \%$ solutions, the $\lambda$ is little affected by PG content because the hydrogen bonding rules over the individual molecular motions. However, $6 \mathrm{wt} \%$ solutions of PG contents more than $30 \mathrm{wt} \%, \lambda$ is decreased particularly at high frequency because the shear induced breakdown of pseudostructure increases chain mobility and leads to faster relaxation.

Physical Properties of PVA/PG Cast Film. The DMTA is a sensitive method that can detect the molecular relax- 
Table II. Thermal Properties of PVA/PG Films Measured by DMTA and DSC

\begin{tabular}{rccccc}
\hline $\mathrm{PG}$ & $T_{g}^{a}\left({ }^{\circ} \mathrm{C}\right)$ & $T_{m}{ }^{b}\left({ }^{\circ} \mathrm{C}\right)$ & $\Delta H_{m}{ }^{b}(\mathrm{~J} / \mathrm{g})$ & $T_{c}^{b}\left({ }^{\circ} \mathrm{C}\right)$ & $\Delta H_{c}^{b}(\mathrm{~J} / \mathrm{g})$ \\
\hline 0 & 61.2 & 225.8 & 65.7 & 199.3 & 65.8 \\
10 & 58.9 & 225.4 & 62.3 & 198.2 & 61.4 \\
20 & 57.9 & 225.1 & 63.8 & 198.9 & 63.0 \\
30 & 56.1 & 224.2 & 52.7 & 195.7 & 53.9 \\
40 & 52.3 & 220.2 & 53.9 & 193.7 & 54.4 \\
\hline
\end{tabular}

${ }^{a}$ Values obtained from the $\tan \delta$ peak of the DMTA. ${ }^{b}$ Values measured from DSC heating and cooling traces at $10^{\circ} \mathrm{C} / \mathrm{min}$, respectively.
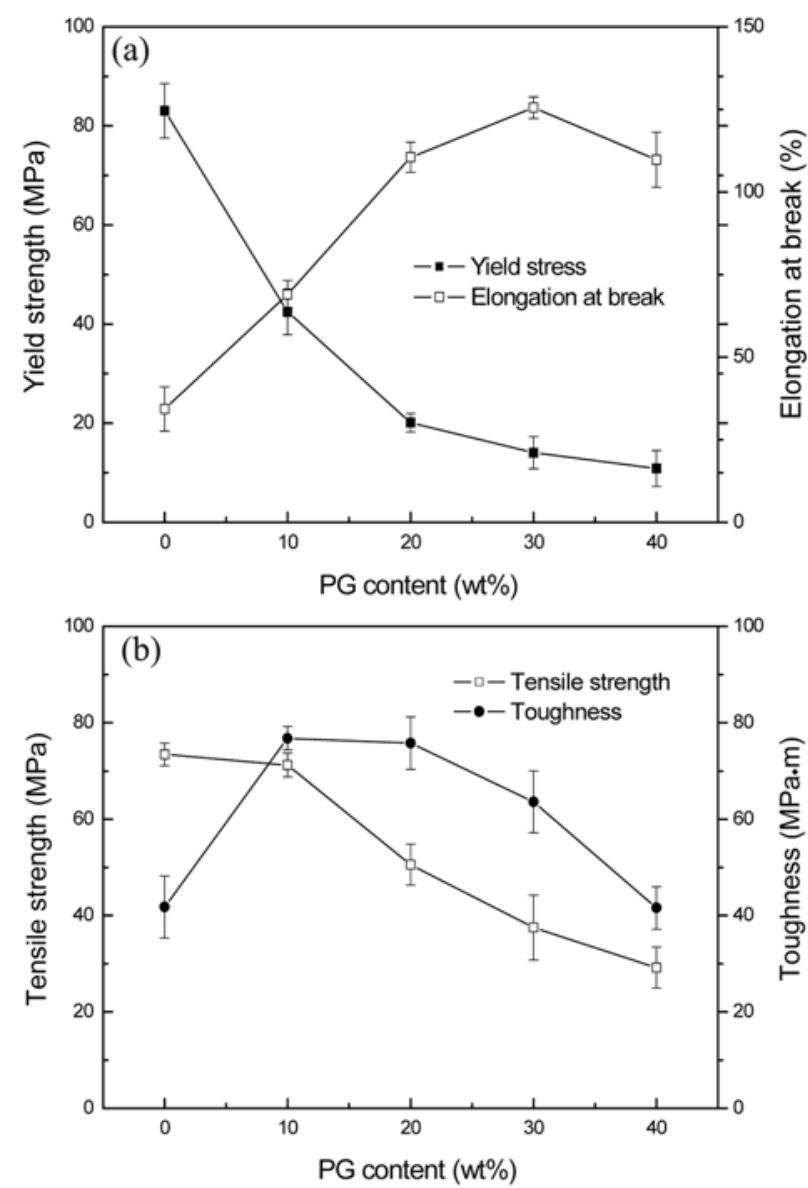

Figure 6. Tensile properties of PVA/PG cast films with PG content.

ations of polymeric materials. In general, $T_{g}$ obtained by this method proved much more reliable than that by other thermal methods such as DSC. The values of $T_{g}$ obtained from the $\tan \delta$ peak of PVA/PG films are given in Table II. As expected $T_{g}$ is linearly shifted to lower temperature with increasing PG content. However, a nonlinear reduction in $T_{g}$ was observed above the plasticizer content $30 \mathrm{wt} \%$. DSC results for the PVA/PG film as a function of PG content at the scan rate of $10^{\circ} \mathrm{C} / \mathrm{min}$ are also given in Table II. As the amount of PG is increased both $T_{m}$ and $T_{c}$ were decreased. This is because of the increased PVA segmental mobility due to the cooperative motion of low molecular weight PG molecules.

The tensile properties of PVA/PG films with PG content measured from the stress-strain curves are shown in Figure 6. As expected the hard brittle properties change to the soft tough properties with increasing PG content. As PG content increases yield stress and tensile strength of the films are decreased but elongation at break is increased. The ability of polymeric materials to absorb energy is a function of strength and ductility (or elongation), which tend to be inversely related. Toughness is the total absorbable energy, which is proportional to the area within the lines drawn on the stress-strain curve from axes. In consequence, toughness of the films is highest between 10 and $20 \mathrm{wt} \%$ of PG content. It is because the increment of elongation at break prevails over the decrement of tensile stress.

\section{Conclusions}

In the case of PVA/PG solutions in DMSO hydrogen bonding is significantly affected by PG content. The intermolecular interactions in the PVA solutions were notably reduced by PG because of its hydrogen bond breaking effects. The critical concentration of PG leading to an abrupt decrease of hydrogen bond proved 20 to $30 \mathrm{wt} \%$. This result agreed with the thermal and mechanical properties of PVA/PG cast films. Thus rheological measurement could offer a measure of the hydrogen bond breaking activity of PG in PVA solutions and films. This result may be effectively utilized in the formulation of PVA films for electronic applications.

\section{References}

(1) B. Briscoe, P. Luckham, and S. Zhu, Polymer, 41, 3851 (2000).

(2) H. Byun, B. Hong, S. Y. Nam, S. Y. Jung, J. W. Rhim, S. B. Lee, and G. Y. Moon, Macromol. Res., 16, 189 (2008).

(3) S. Oda, J. I. Tanaka, H. Ohta, and J. Ferment, Bioeng., 86, 84 (1998).

(4) J. K. Yun, H. J. Yoo, and H. D. Kim, Macromol. Res., 15, 22 (2007).

(5) T. Kajiyama, Macromol. Res., 15, 109 (2007).

(6) J. H. Kim, B. R. Min, Y. W. Kim, S. W. Kang, J. Won, and Y. S. Kang, Macromol. Res., 15, 343 (2007).

(7) J. H. Choi, S. Ko, B. C. Kim, J. Blackwell, and W. S. Lyoo, Macromolecules, 34, 2964 (2001).

(8) W. S. Lyoo, J. H. Choi, B. C. Kim, and J. Blackwell, Macromolecules, 34, 3982 (2001).

(9) D. K. Lee, J. T. Park, J. K. Choi, D. K. Roh, J. H. Lee, Y. G. Shul, and J. H. Kim, Macromol. Res., 16, 549 (2008).

(10) C. W. Bunn and H. S. Peiser, Nature, 159, 161 (1945).

(11) E. J. Lee, N. H. Kim, K. S. Dan, and B. C. Kim, J. Polym. Sci. Polym. Phys. Ed., 42, 1451 (2004).

(12) E. J. Lee, K. S. Dan, and B. C. Kim, J. Appl. Polym. Sci., 101, 465 (2006).

(13) S. I. Song and B. C. Kim, Polymer, 45, 2381 (2004). 
(14) M. W. Chang and B. C. Kim, Macromol. Symp., 249-250, 591 (2007).

(15) K. G. Wagner, M. Maus, A. Kornherr, and G. Zifferer, Chem. Phys. Lett., 406, 90 (2005).

(16) S. Rajendran, M. Sivakumar, and R. Subadevi, Mat. Lett., 58, 641 (2004).

(17) J. S. Jang and D. K. Lee, Polymer, 44, 8139 (2003).
(18) S. M. Hong, B. C. Kim, S. S. Hwang, and K. U. Kim, Polym. Eng. Sci., 33, 630 (1993).

(19) N. Casson, Rheology of Dispersed Systems, Pergamon, London, 1959.

(20) K. F. Wissbrun and A. C. Griffin, J. Polym. Sci. Polym. Phys. $E d ., 20,1835$ (1982). 